\title{
ESTIMATING INFLUENCE OF RAIL PROFILE SHAPE ON LATERAL WEAR OF RAIL AND WHEEL AFTER GRINDING OF 60E1 AND R65 RAILS
}

\author{
Viktors Ivanovs, Pavels Gavrilovs, Alexander Boiko, Ivo Vaicis \\ Riga Technical University, Latvia \\ viktori4301187@inbox.lv, pavels.gavrilovs@rtu.lv, boyko.af@inbox.lv, ivo.vaicis@rtu.lv
}

\begin{abstract}
The problem of lateral wear intensity for rails and wheels has not been resolved at the present, despite many studies in this area. This article aims to provide evidence of the influence of rail head profile after grinding on the lateral wear of interacting surfaces of rail and wheel in curves and straight sections of $1520 \mathrm{~mm}$ track for Latvian Railways. The article suggests the method of creation of asymmetric repair profiles for rail grinding taking into account the shape of wear for wheel profile. For this purpose, statistical data were collected on the most typical form of wear for wheel profiles of railcars on the Latvian Railway. Asymmetrical profiles for rail grinding have been developed and the basic primary grinding angles for straight and curved sections of the track have been defined by means of geometric modeling. As a result, the contact points of rolling surface of wheels were shifted to the centre of the curve. The difference in wheel radii reached $5.6 \mathrm{~mm}$ in one wheel pair, and the fitting of wheel pairs was improved by 4 times. At the final stage of the study, the corrective profiles for grinding the rail head were developed utilizing SolidWorks Simulation, taking into account the most typical wear of the wheel profile, which increased the contact areas and as a result reduced the stresses up to $18 \%$ on the outer rail in the curve with a radius of $800 \mathrm{~m}$. As a result, for the outer rail, part of the load shifts from the wear zone of the wheel flange to the root of the wheel flange. For safety reasons, the stability coefficient of a worn wheel profile for the Latvian Railways with a flange angle of $66.8^{\circ}$ was calculated in accordance with the rolling mode along developed asymmetric rail profiles. The calculated wheel stability reserve against derailing has a significant reserve. As an alternative to grinding, it was proposed to reduce the tilting of the outer rail and increase the tilting of the inner rail in curves.
\end{abstract}

Keywords: rail, grinding, profile, stress, method.

\section{Introduction}

In international traffic for rolling stock it is permitted to use different wheel profiles on a track of $1520 \mathrm{~mm}$. The conditions of interaction between wheels and rails are different. In the wheel/rail contact pair, rolling friction, sliding friction and impact loads are applied. However, the contact surfaces have a similar pattern of mutual wear. The wear intensity of the wheel flange arc and working radius of the rail is significant, resulting in reduced service life of the wheel pairs and the rail track.

To reduce this wear, various studies are known in the following areas: optimization of suspension stiffness parameters [1], dynamic analysis of wheel/rail [1;3], thermal model taking into account the change of material properties from the temperature at braking [2], rail profile measurement by introducing additional measuring sensors $0^{\circ}$ and $45^{\circ}$ [4], lubrication of rails in curves [5; 18], modeling of FEM on curves of small radius in non-elastic and elastic setting of the problem [6; 7], optimization of wheel hardness [8], optimization of methods of creation of meshes of finite element contact models [9]. The advantage of these studies is a detailed description of the influence of one or more factors on wear. However, the disadvantage of studies known to the authors is the lack of consideration of real wear of the wheel profile when modeling the interaction with a new or worn rail for grinding. In normative documents [10-14] there is also no requirement to take into account real wheel wear when creating a repair profile of rail grinding, which causes mismatch of wheel and rail profiles and high stress level and increase of wear intensity.

Therefore, in spite of a great number of works in this area $[1-9 ; 18]$, the problem of rail and wheel wear intensity is not solved at the moment, and therefore insufficiently researched. Restoration of rail and wheel profiles is expensive. In addition, wheel pairs are currently a deficit on the market. Therefore, increasing the service life of wheel pairs and rails is one of the main tasks of rail transport.

\section{Analysis of wheel and rail wear}

On the Latvian Railway, the length of straight sections of railway tracks is small, resulting in the movement of railcars on a large number of mainline tracks with a radius of $R=800 \mathrm{~m}$. As a result, the influence of horizontal forces on wheels and rails is significant. Profiles of wheel tread have different transition radii from the tread surface to the flange [10]. On the Latvian Railway, the R65 rails are 
almost replaced by EN60E1 rails [11]. The radius from the side face of the rail head to the tread surface has been changed from $15 \mathrm{~mm}$ to $13 \mathrm{~mm}$, respectively. The run-in time of the applied wheels to the rail has been reduced, causing the transfer of part of the load to the flange (one point or twopoint contact). The most frequent defects of the wheel pairs of the Latvian Railway from 2016 to 2019 are shown in Table 1.

Wheel pair reject statistics on the Latvian Railway from 2016 to 2019 year

Table 1

\begin{tabular}{|c|c|c|c|c|}
\hline Major wheel faults & $\mathbf{2 0 1 6}$ & $\mathbf{2 0 1 7}$ & $\mathbf{2 0 1 8}$ & $\mathbf{2 0 1 9}$ \\
\hline Arris $^{1}$ & 63 & 20 & 8 & 6 \\
\hline Spalls $^{2}$ & 155 & 172 & 257 & 249 \\
\hline Scales $^{3}$ and skids $^{4}$ & 158 & 145 & 315 & 218 \\
\hline Thin flange $^{5}$ & 51 & 64 & 96 & 109 \\
\hline Total number: $^{2}$ & 427 & 401 & 676 & 582 \\
\hline
\end{tabular}

An arris $($ Table 1,1$)$ is formed when flange metal has rolled towards the tip of the flange causing a step with a sharp point at the flange tip of railway wheel.

Spalling (Table 1,2) or shelled tread occurs when pieces of metal break out of the tread surface of railway wheel in several places more or less continuously around the tread circumference. This defect can result from thermal damage, skidding or over-stressing at the wheel-rail contact point. Any circular cracks associated with the early stages of spalling are this defect. Pitting may also be noticed.

Scaling (Table 1,3) is the build up of metallic material on the surface of the wheel tread, giving the tread a scaly appearance. It is usually attributed to sticking brakes which cause the wheel to slip or slide on the rail, thus heating it to the stage where the material becomes soft enough to flow on the tread surface.

Skids (Table 1,4) occur when a wheel "locks up" while the rail vehicle is moving. All skids eventually lead to further wheel damage such as spalling and reduce the life of bogie components such as bearings.

For detecting a thin flange (Table 1,5 ) of wheel is using a thin flange measurement gauge with certain clearance. A thin flange will be detected when the end of the measurement gauge touches the tread surface of the wheel.

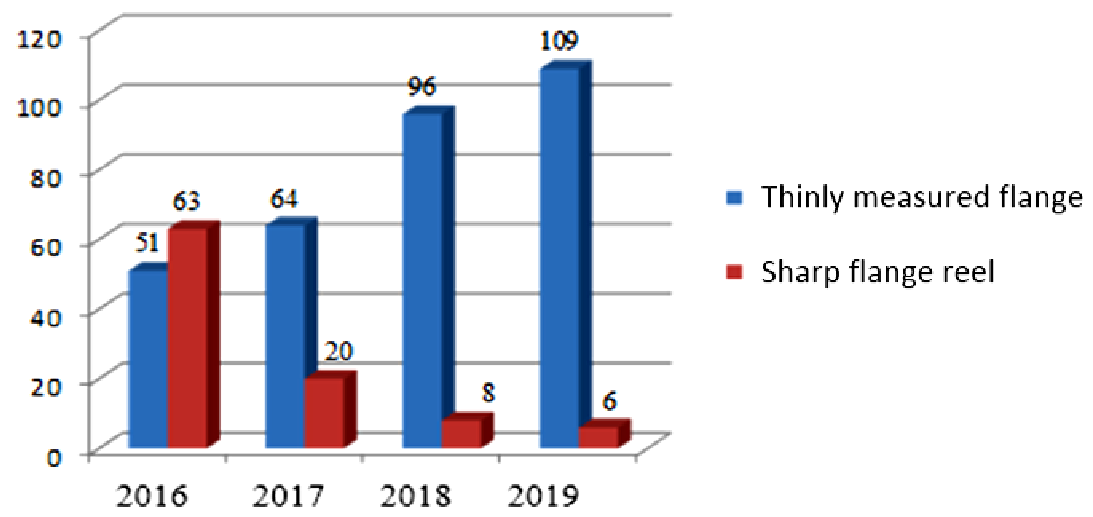

Fig. 1. Main defects of wheel pairs in interaction with the rail on the Latvian Railways in the period from 2016 to 2019

Thus, the main defects of wheel pairs arising from the mutual wear of the wheel and the rail head are a thin flange and aris, which is formed by a two-point contact Table 1 . The intensity of the wheel flange thickness reduction has increased by $53 \%$ within 4 years Fig. 1. Similar situation with wheel pairs wear is in the USA, Ukraine, Belarus, Russia countries. Thus, on the Russian Railway participating in international communication the maximum flange wear of wheel pairs is $44.09 \%$; the permissible excess of rim diameter difference is $25.64 \%$; vertical undercutting of the flange (thin flange) is $15.27 \%$; influx of metal on the outer edge is $4.73 \%$; skids are $3.18 \%$ and etc.

The results of measurements of wheel profiles in operation also confirm that at long runs the wheel tread wears out Fig. 2a and at short runs with frequent curves the greatest wear is located in the 
root and face area of the flange Fig. 2b. On the presented profile of the Latvian Railway, the tread wear of wheels reaches 1-2 mm only but flange wear of wheels reaches $6.5 \mathrm{~mm}$, which corresponds to the results of statistics in Fig. 1. Therefore, wear of wheel flange is relevant for the Latvian Railway.

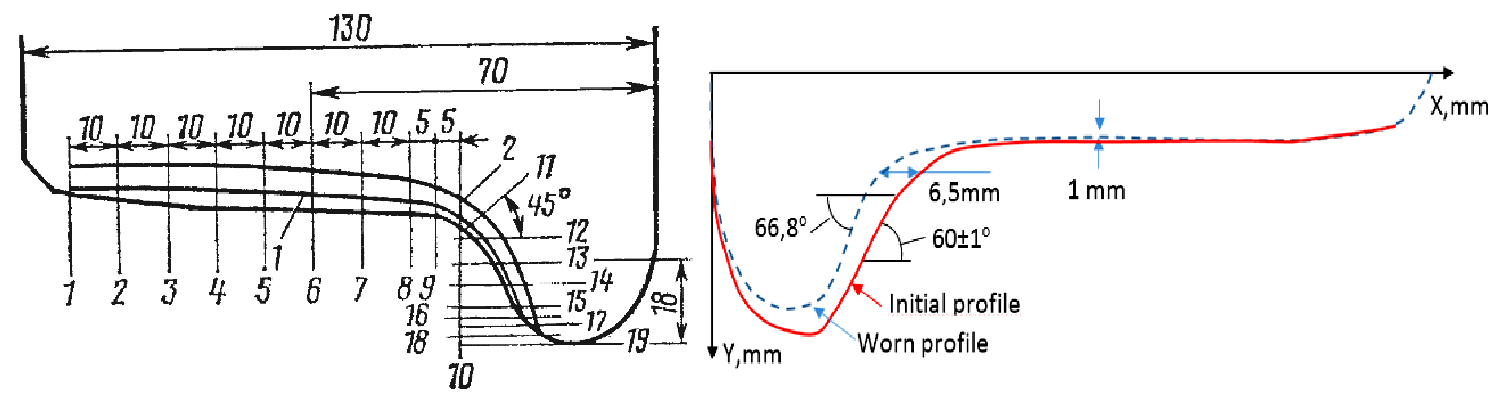

a)

b)

Fig. 2. Major profiles of worn wheels (a) and typical wheel wear on the Latvian Railway (b): 1 - medium wear; 2 - maximum wear on the Russian railways; 1-19-rim sections

Mutual influence of the wheel on the rail results in wear of the side edge of the rail, which occurs in the rails of track curves, due to friction between the working (side) edge of the rail and the wheel flange. A number of measurements were made by means of the track caliper of the PCHV type (TU 3933-002-060632410-2012) to determine the average wear of the rail head on the Latvian Railway network. Figure 3 a shows the wear of the side edge of the rail.

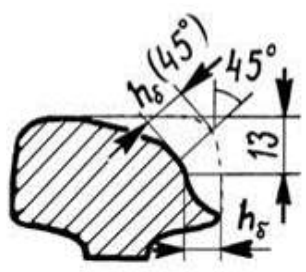

a)

Fig. 3. Lateral wear of rail: a - measurement scheme in the $R=708 \mathrm{~m}$ curve and 60E1 rail. Vecumneki station, b - R65 rail on Russian Railway, Nikolaevka station

The lateral wear of the rail head is $12 \mathrm{~mm}$, measured at $13 \mathrm{~mm}$ below the rail head level Fig. $3 \mathrm{a}$. In Figure $3 b$, the lateral wear of the rail is two times smaller. The $60 \mathrm{E} 1$ rail has a vertical wear of $3 \mathrm{~mm}$. The indicated wear on the rail is $9 \mathrm{~mm}$, which is a defective case [10]. According to [12], this defect is caused by increased slope of the wheel flanges. This is caused by increased angles of the wheel flanges and pressing over on the side edge of the rail in the track curves, as well as the lack or insufficient lubrication of the side edge of the rail head. In the case of tilting irregularities in straight track sections, lateral wear of the rails is generated, which extends from 1 to 30 metres along the length of the track.

Figure 4 shows short periodic unevenness - short pitch corrugation of the outer rail head on curve, length from 3 to $25 \mathrm{~cm}$. The short pitch corrugation of rail defect arises due to insufficient difference in $\mathrm{R} 1$ and $\mathrm{R} 2$ radii of tread in one-wheel pair, since the outer wheel to travel a longer distance than the inner wheel, this causes the outer wheel to slide Fig. 5. To avoid this, it is necessary to create an asymmetric rail profiles on curve by grinding.

The tilt of the rails and wheel tread profile of the wheels according to $[10 ; 11]$ is $1: 20$ in relation to the horizontal axis of the used wheels and rails Fig. 5. Excess railcar speeds in rail curves causes an increase in lateral load on the rail Fig. 3a and excessive wheel slope relative to the rail Fig. 4.

Disruption of tilt of rails, value of superelevation of high rails and wheel profile (their wear) contributes to defects of rails and wheels Fig. 1-4. 


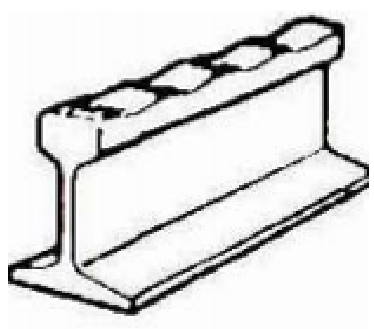

Fig. 4. Short pitch corrugation of rail

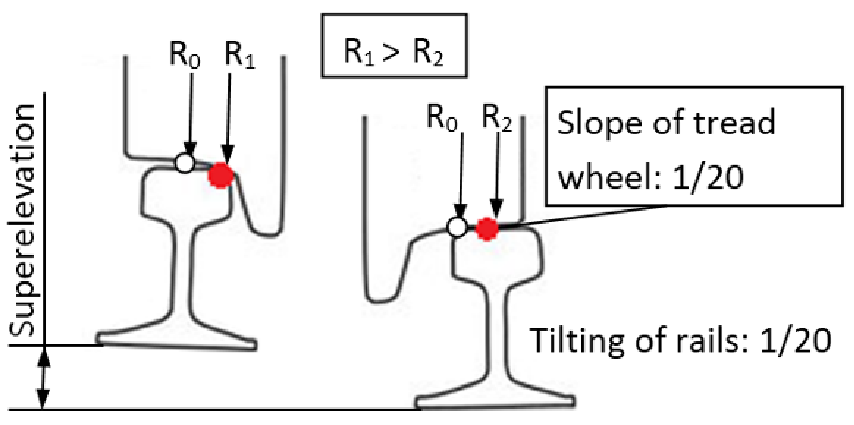

Fig. 5. Tilting of rails and slope of wheel tread

\section{Analysis of rail grinding profiles}

The rail is grinded to eliminate defects. According to the technological process for railgrinder train SPENO repair profiles are designed to repeat the initial profile of rail Fig. 6, taking into account the wear of the rail in 3-4 mm increments [13]. The normative documentation [14] recommends grinding to repair asymmetrical profiles for inner and outer rails, taking into account the lateral wear of the rail in $5 \mathrm{~mm}$ increments Fig. 7. There are known ways [4] to describe the repair profile more precisely by inserting additional points into the repair profile Fig. 8. There are also known methods [13 ] of dynamic simulation of rolling stock with the analysis of wheel/rail stresses.
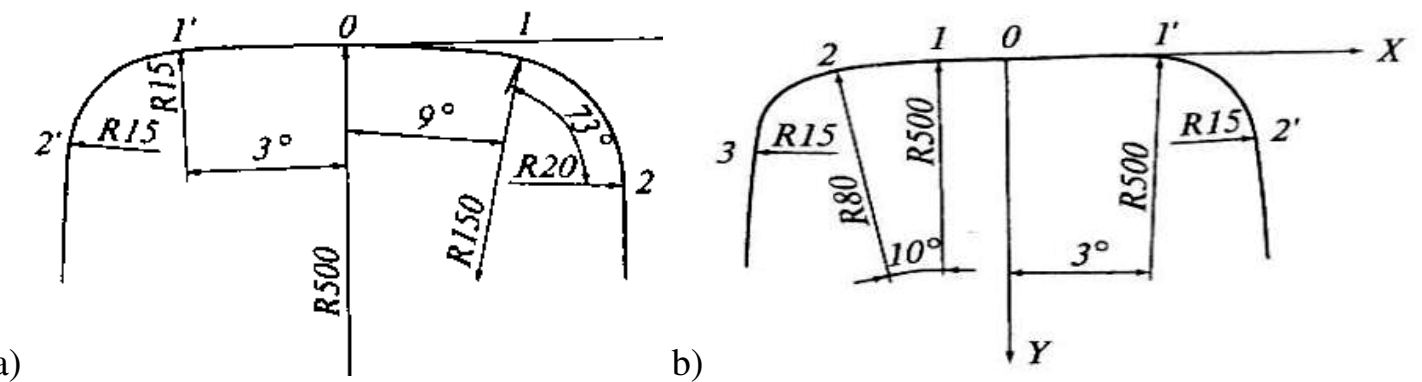

Fig. 6. Repair rail profiles with vertical wear $1-4 \mathrm{~mm}$ with missing tonnage from 150 to 500 million tonnes gross in curves $\boldsymbol{R}=\mathbf{8 0 0 - 1 0 0 0} \mathbf{~ m}$ : a - high rail; $\mathrm{b}$ - low rail

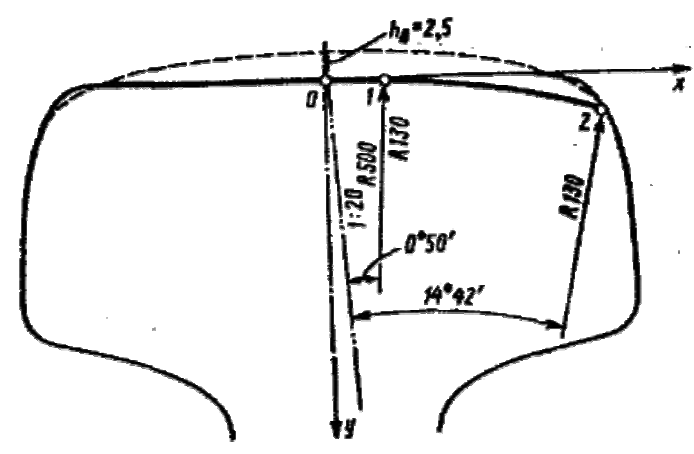

a)

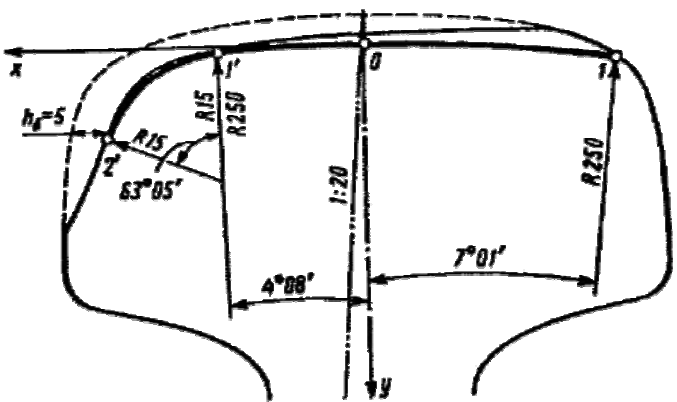

b)

Fig. 7. Repair asymmetrical rail profile P65: a - inner rail, vertical wear $2.5 \mathrm{~mm}$; $\mathrm{b}$ - outer rail, lateral wear in curves $5 \mathrm{~mm}$

The above-mentioned methods and approaches for rail head profile restoration by grinding are based on the repetition of an initial rail profile. Considering the high rate of wear on the wheel/rail pair, it can be concluded that these methods are not sufficiently effective.

Moreover, rail grinding on the Latvian Railways is carried out by order of the Swiss company SPENO. When ordering a grinding service, the contractor is informed of the type of rail, the location of the rail track to be grinded, and does not provide information on wheel pair profiles condition. 
Wheel and rail surfaces are not coordinated under these conditions. The issue is not fully researched and new approaches must be found.

a)

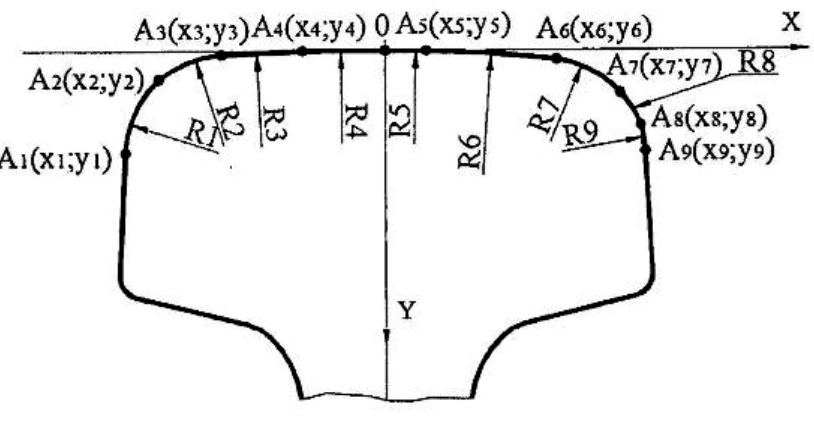

b)

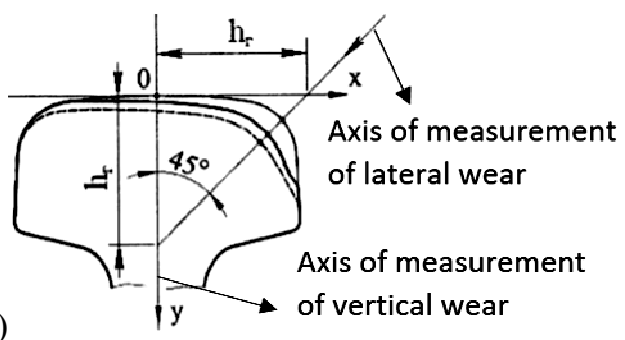

Fig. 8. Profile refinement of the rail by: $\mathrm{a}$ - additional points; $\mathrm{b}$ - additional measuring axes

\section{Method for creating repair profiles for rail grinding}

A pair of friction between wheel and rail results in mutual wear on the contact surfaces. Therefore, it is suggested to look for a repair profile shape for grinding rails taking into account the wheel wear profile. Of course, the task is compounded by the wide variety of wheel profiles that have been put into operation. Also, when the tread wear of the wheel profiles is $1-2 \mathrm{~mm}$, the slope of the tread wheel changes, the contact points move horizontally relative to the rail, the type of contact and the process of the wear changes accordingly. In addition, with such an unaccounted wheel profile, the wheel radii in one-wheel pair tend to become the same, which is particularly unacceptable in curved areas of the rail track.

For this reason, it is proposed to collect statistics on the main forms of wear for the wheel profiles in used. The information should be sorted by the shape of wheel profiles and the nature of wear on Latvian Railways in general or by traffic sections. In this way separate sections with similar wear on rails will be identified. It will then be possible to solve the task of creating rail profiles for grinding wheels that have been matched to the profiles. The development of more rail profiles for preventive and repair grinding with finer discrete vertical and horizontal mutual wheel/rail wear will reduce the amount of metal removed from the rail and reduce the grinding time.

\section{Results of modelling of rail repair profiles}

On the basis of the collected data on wheel wear Fig. 2 and rail Fig. 3 we estimate their contact interaction geometrically. Let us perform 3D modeling of wheels GOST-10791 [10] and rail 60E1 [11] in SolidWorks programme. Evaluation of the contact form was simulated for unworn and worn rails and wheels in different combinations. The most dangerous types of contacts, subject to further stress assessment, are shown in Fig. 9 for straight and curved track sections with a radius of 800 metres respectively.

As a result of the variant modeling it was found out that on the straight sections of the track the contact in the middle zone of the wheel and the rail prevails, which does not cause thinning of the flange - single-point contact. In the curves, a two-point contact is formed, which promotes the formation of a thin flange. Therefore, based on the location of the interaction zones on the wheel-rail contact surfaces, asymmetrical profiles for grinding the rail with a radius of $800 \mathrm{~m}$ are developed for the track, taking into account the wheel profile, which is typical for Latvian Railways.

As a result of the evaluation of the influence of different rail grinding profiles on the interaction in the wheel/rail friction pair, the efficiency of profiles for rail grinding developed by the authors has been confirmed Fig. 9g, 9h. Wheel/rail contact zones are shifted to the centre of the track curve with the offset being from $5 \mathrm{~mm}$ to $18 \mathrm{~mm}$ on the inner rail and the wheel radius being reduced from $0.44 \mathrm{~mm}$ to $2.6 \mathrm{~mm}$, and on the outer rail from $18 \mathrm{~mm}$ to $32 \mathrm{~mm}$ and the wheel radius being increased from $1.69 \mathrm{~mm}$ to $3.27 \mathrm{~mm}$. The difference between the inner and outer wheel radii of the profiles used varies from $1.36 \mathrm{~mm}$ to $2.96 \mathrm{~mm}$, and the highest value of $5.66 \mathrm{~mm}$ is achieved with the profiles proposed in this article. The increase of the radius difference allows to improve the fit of wheel pairs 
by 4 times in this case the contact is single-point and does not affect the flange area in the simulated curves with radius of about 800 metres.

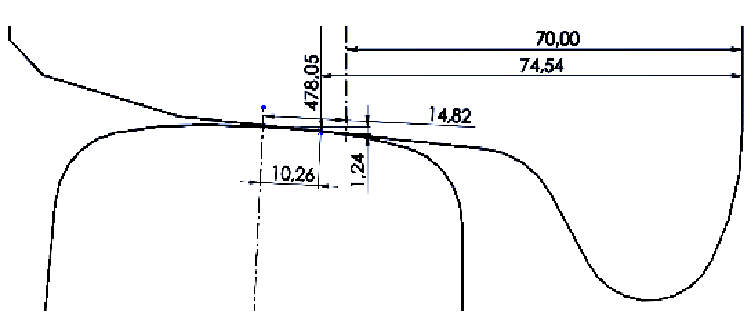

a) contact offset $O=-10.26 \mathrm{~mm}, R_{I}=478.05 \mathrm{~mm}$

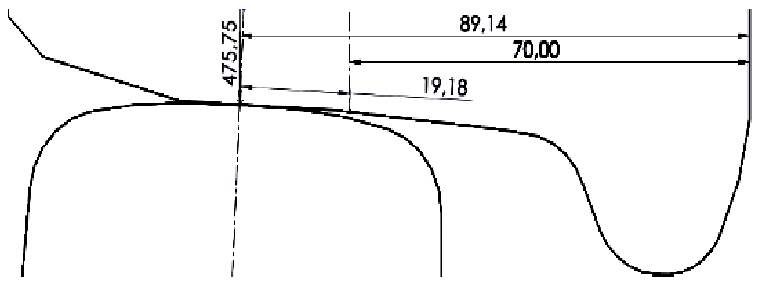

c) $O=0 \mathrm{~mm}, R_{I}=475.75 \mathrm{~mm}$

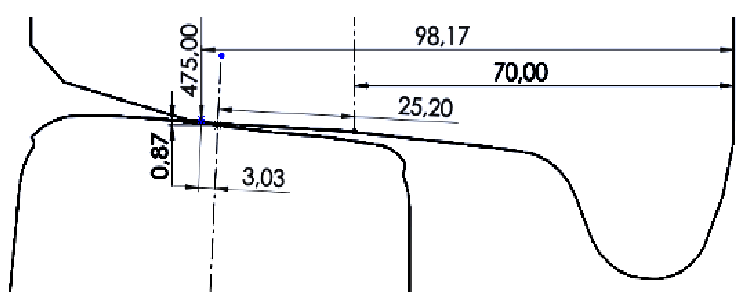

e) $O=3.03 \mathrm{~mm}, R_{I}=475 \mathrm{~mm}$

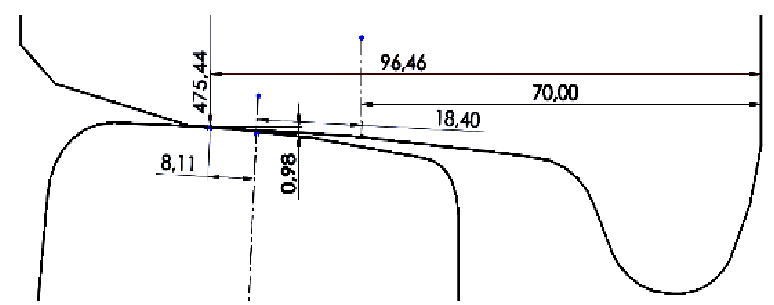

g) $O=8.11 \mathrm{~mm}, R_{I}=475.44 \mathrm{~mm}$

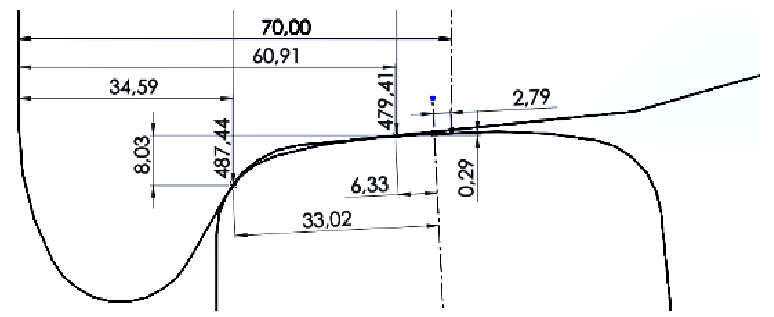

b) $O=8.03 \mathrm{~mm}, \Delta R_{o}=8.03 \mathrm{~mm}$

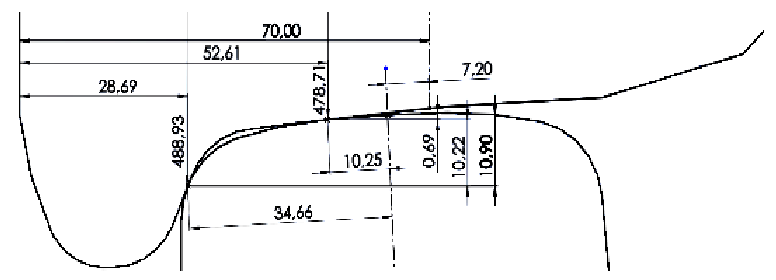

d) $O=10.9 \mathrm{~mm}, \Delta R_{o}=10.22 \mathrm{~mm}$

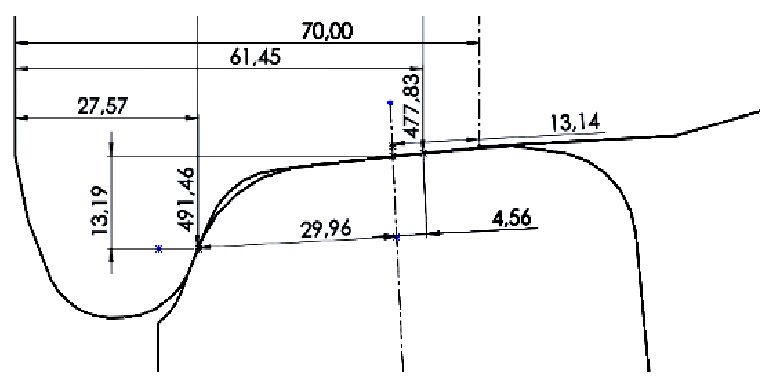

f) $O=13.19 \mathrm{~mm}, \Delta R_{o}=13.63 \mathrm{~mm}$

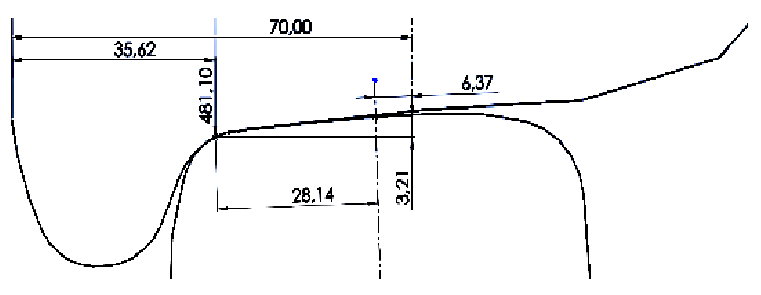

h) $O=28.14 \mathrm{~mm}, R_{o}=481.10 \mathrm{~mm}$

Fig. 9. Contact location, rail 60E1, wheel GOST-10791: on curve $a, b$ - unworn rail (grinding to initial profile) - unworn wheel; c, d - unworn rail - wheel lateral wear $6.5 \mathrm{~mm}$; e, f - vertical wear of inner rail $2.5 \mathrm{~mm}$, lateral wear of outher rail $6 \mathrm{~mm}$ and vertical wear $1.5 \mathrm{~mm}$ - wheel wear $6.5 \mathrm{~mm}$; $\mathrm{g}, \mathrm{h}$ - authors designed rail grinding profile - wheel wear $6.5 \mathrm{~mm}$; a, c, e, g $-R_{I}$ - wheel radius in contact with inner rail; $\mathrm{b}, \mathrm{d}, \mathrm{f}, \mathrm{h}-\Delta R_{o}-$ wheel radius deviation in two contact of outer rail profile

Figure 10 gives the designed asymmetric-grinding profiles for the inner and outer rails. Among them, a pair of rail asymmetric profiles with lower wheel-rail interaction and less grinding amount was determined as the recommended profiles for rail grinding Fig. 10b, 10c. Compared with the inner rail profile, the grinding range of the outer rail profile is larger and its grinding zones spread over the rail side and rail top. The inner rail profile is mainly ground in the local region of rail top. The main grinding angles of asymmetrical profile surfaces reach from $2.68^{\circ}$ to $2.41^{\circ}$ for the outer rail and from $2.36^{\circ}$ to $4.61^{\circ}$ for the inner rail.

To assess the impact of rail grinding we will perform 3D modeling of wheel/rail pair interaction using the developed rail profile. Let us estimate the level of stresses by means of Solidworks Simulation. 
a)
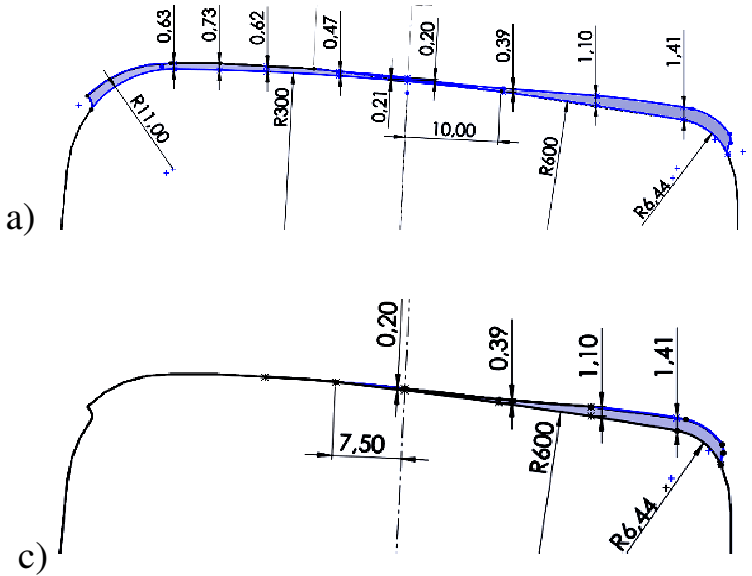

b)

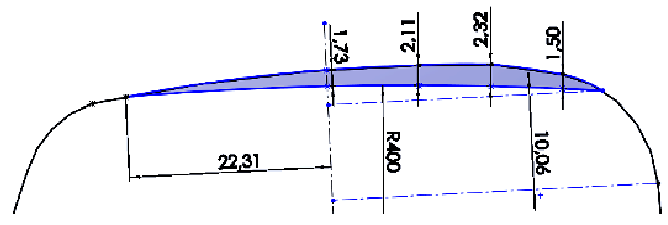

d)

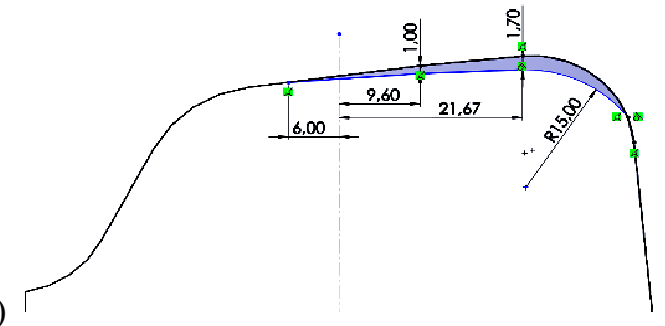

Fig. 10. Designed repair profiles for rail grinding: on straight gauge: a - for worn rail profile on Latvian railway; on curve 800 m radius: $b, d$ - for worn profile of outer rail and for profile with wear threshold, $\mathrm{c}$ - for unworn and worn profile $2.5 \mathrm{~mm}$ of inner rail

The objects of research are rail 60E1 [11], and whole-rolled wheel GOST-10791 [10] Fig. 2, wheel pair of freight car weighing 100 tons. The model is axi-symmetric, so it is possible to consider a quarter wheel. In operation, the size of the contact area is 13-16 mm [15], and the contact area with the flange, depending on the angle of the wheel to the rail - angle of attack, is shifted forward [16]. To reduce machine time, remove the wheel hub and wheel rim from the wheel model. For straight track calculation we use wheel model as a sector with angle of 90 degrees and rail length of $50 \mathrm{~mm}$. When calculating the track curve, we use the rail model length of $80 \mathrm{~mm}$ Fig. 11. As a result of optimization of the finite element mesh of the model, the size of finite elements in the transition areas is $1.4 \mathrm{~mm}$ for contact surfaces, and in the regular areas we accept $9 \mathrm{~mm}$ Fig. $11 \mathrm{~b}$.
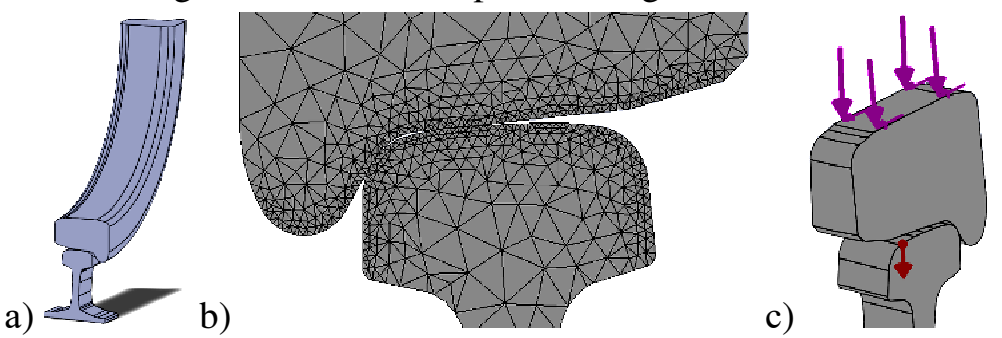

Fig. 11. Calculation model of wheel and rail: $\mathrm{a}$ - in straight track; $\mathrm{b}$ - finite element mesh; $\mathrm{c}$ - applied loads, model fragment

A vertical load of $1 / 8$ of the freght car weight is applied to the model. Then the load is recalculated to the wheel sector with an angle of 90 degrees. Uneven load from the freight car weight is applied to the upper surface of the wheel sector, according to the law of load distribution from the wheel pair axis to the wheel hub opening. Density of wheel and rail materials is taken into account. When examining the passage of a wheel in radius curves, the lateral load is also applied in the transverse direction of the wheel to the upper surface of the wheel Fig. 11c.

In order to evaluate the accuracy of the created test models, the sizes of the wheel/rail contact pads GOST-10791 and R65 Fig. 12 have been compared. The dimensions of the contact pads of the wheel/rail design model, obtained by modeling $14.26-18.28 \mathrm{~mm}$, correspond well with those obtained by Hertz theory $14.8 \mathrm{~mm}$ and with the operation data $-13-16 \mathrm{~mm}$ [15]. The levels of stresses in the developed design wheel/rail models based on a linear-elastic material model range from 700 to $2400 \mathrm{MPa}$ and are consistent with the results of other authors $[6 ; 8 ; 9 ; 15]$ with a $10-12 \%$ increase in levels relative to the model based on a nonlinear material model. However, for this model the main objective is to compare the impact of grinding on relatively new and worn rails and wheels in operation on the Latvian Railway. 

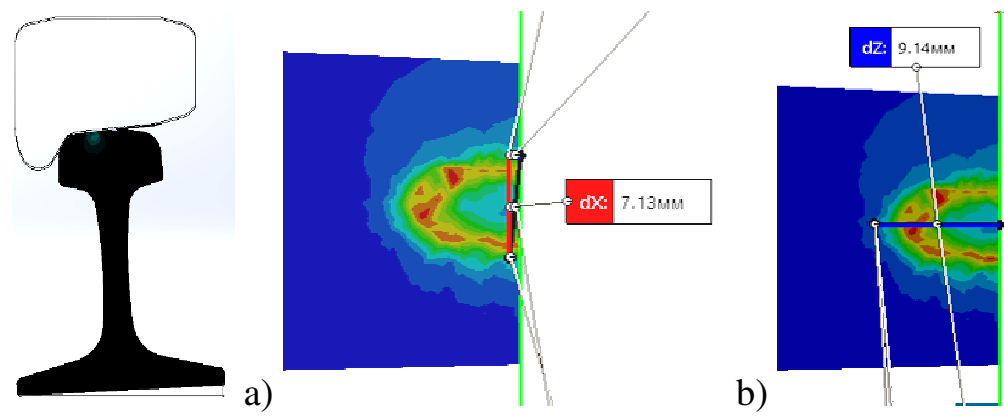

Fig. 12. Contact area on the rail in direction: $a$ - horizontal; $b$ - longitudinal

\section{Results of calculation of stresses}

Taking into account the results of geometric modeling of contact zones, we can calculate the stresses of wheel and rail for straight track and curve with radius of 800 metres. We choose the initial profile of rail 60E1, worn and newly developed asymmetric repair (grinded) rail profile Fig. 10. Wheel GOST-10791 is chosen with characteristic wear for Latvian railway Fig. 2b. The results of calculations are presented in Fig.13, 14.

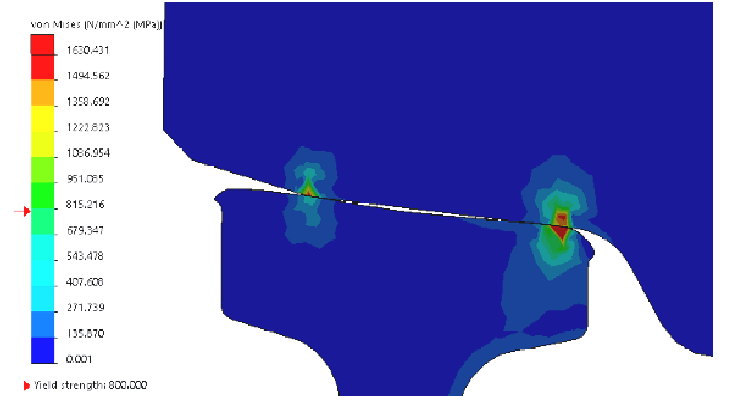

a) rail axle offset $-5 \mathrm{~mm}$

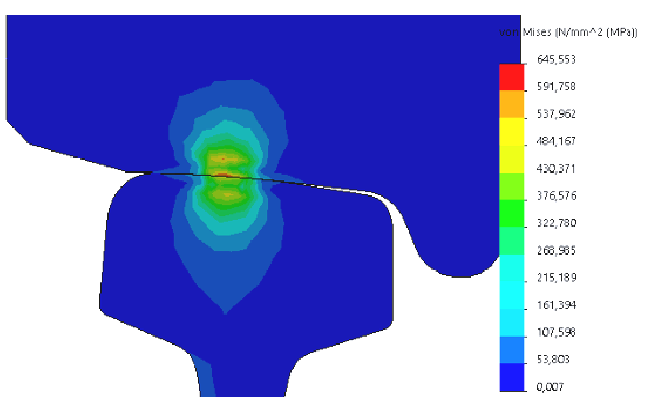

c) raile axle nominal offset $-4 \mathrm{~mm}$

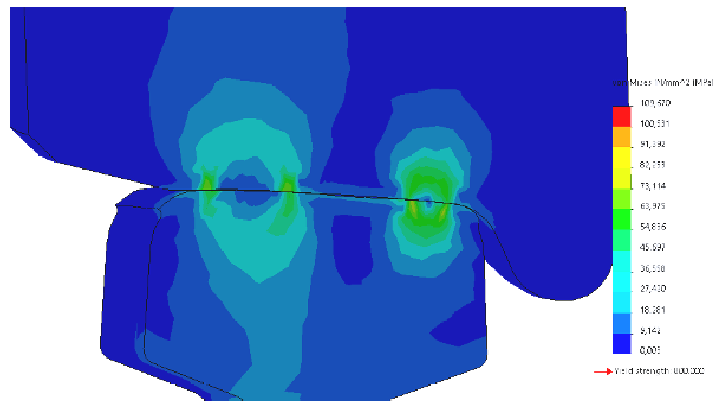

b) rail axle maximal offset

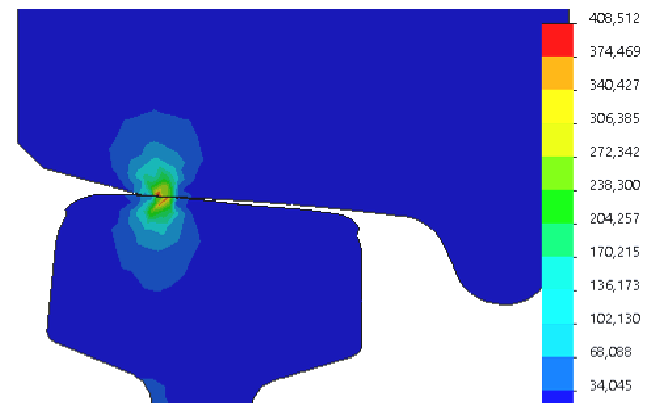

d) rail axle offset $6.4 \mathrm{~mm}$

Fig. 13. Von Mises stresses of wheel worn profiles on Latvian railway and rail: on straight gauge ( $\mathrm{a}$ - maximal wear of rail profile; b - rail wear $2.5 \mathrm{~mm}$; c-designed rail profile Fig. 10a); inner rail on curve $(\mathrm{d}-$ designed rail profiles Fig. 10c)

On a straight track at the interaction of worn wheel and rail profiles the stress level of $1630 \mathrm{MPa}$ exceeds the yield strength of the material Fig. 13. Using the developed rail profile Fig. 10a, the stresses are reduced to $640 \mathrm{MPa}$. At interaction of wheel and rail in the track curve, the stress level was $1770 \mathrm{MPa}$ on the outer rail at single-point contact and $620 \mathrm{MPa}$ at double-point contact Fig. 14a,14b. After corrective grinding of the rail, the stresses were reduced to $510 \mathrm{MPa}$ in the area of the working radius Fig. 14c, 14d. On the inner rail, stresses reach $450 \mathrm{MPa}$ Fig. 13d when using the developed rail profile, Fig. 10c.

As shown in Fig. 13c, using the developed rail profile Fig. 10a, 10c will allow the contact area to be shifted outwards in the straight track to an area with less wheel and rail wear Fig. 2b, 13a. This solution will contribute to a more even wear of the rail and wheel profiles. As shown in Fig. 14d, the use of the developed profile Fig. $10 \mathrm{~b}$ and corrective grinding on profile $14 \mathrm{c}$ will eliminate the contact 
zone of the outer rail with the wheel flange surface in the curve. When grinding on these profiles it is possible to form a single-point contact with a larger area than that of the used rail grinding profiles. It is also possible to form a two-point contact as in Fig. 14b with small gaps of 1.0-1.2 $\mathrm{mm}$ in the area of the root of the wheel flange. After the surfaces of the outer rail and wheels have been worked on, the profile of the rail and wheels will move into a conformal position with clearances of 0.4-0.6 mm [17] at the root of the flange. After the run-in of contact profiles, it is necessary to perform correction of rail profiles repeatedly, according to the method suggested in this article, taking into account changes of wheel profiles in the track section provided for grinding Fig 10c, 14c.

a)

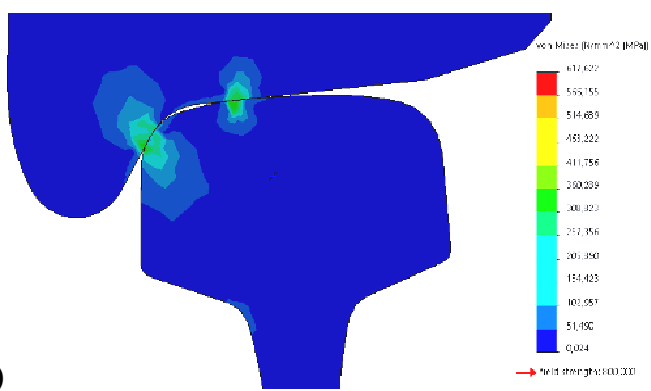

c)

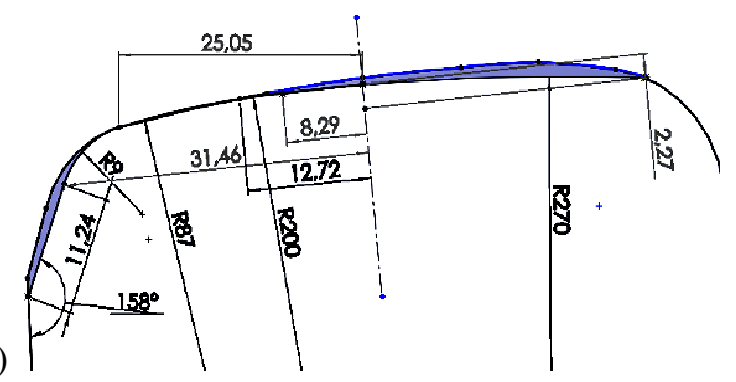

b)
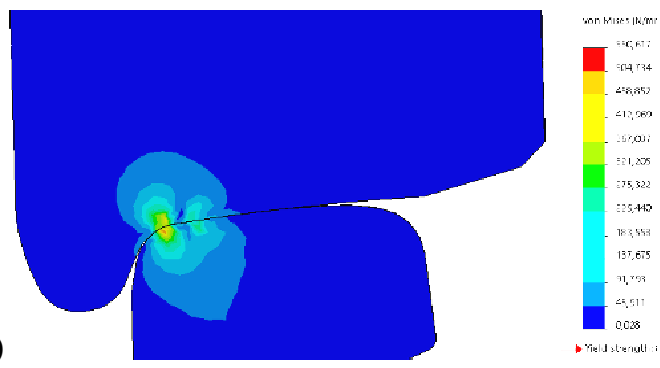

d)

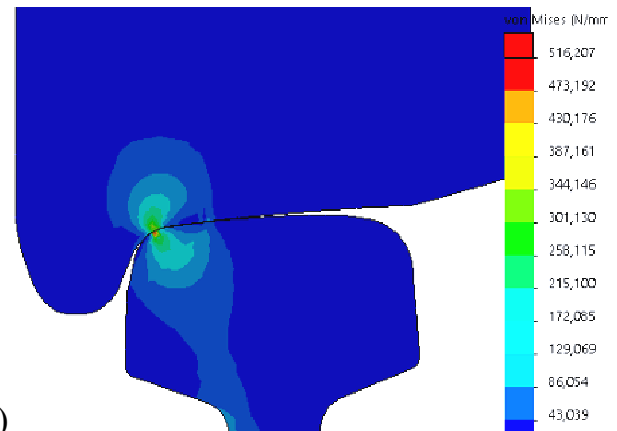

Fig. 14. Von Mises stresses of wheel worn profiles on Latvian railway and outher rail on curve gauge: $a$ - stress of unworn outher rail profile; $b$ - stress in root zone of flange for rail wear $2.5 \mathrm{~mm}$; $\mathrm{c}$ - designed rail profile adjusted to ginding in radius zone; $\mathrm{d}-$ stress zone offset from the flange when using designed outher rail profile Fig. 10b, 14c

The optimum profile is a compromise between of wheel pair stability and wear. Therefore, calculation of the stability coefficient of worn wheel profiles with a flange angle of 66.8 degrees, as shown in Fig. 2b, according to the condition of rolling onto rail profiles developed in this article was performed. The calculated coefficient was 2.95 , which exceeds the minimum permissible value of 1.5 for freight cars and confirms the stability reserve and operational safety.

Thus, knowing the wear of wheels and the size of their turning it is necessary to change the grinding angles and bring the profile of the rail closer to the wheel. In the track curve, the radius of the outer rail on the working side is smaller than the root of the wheel flange. With this grinding variant, the wheel/rail contact will tend to a pre-conformal two-point contact with an insignificant gap at the root of flange, or to a single-point contact without contact with the wheel flange, but only with its root.

\section{Recommendations}

We suggest using the developed calculation asymmetric profiles for grinding the external and internal rails in curves on the Latvian Railway at the wear and forms of wheel profiles close to those specified in the article. Taking into account the grinding angles of the developed rail profiles, we suggest reducing the inclination of the outer rail to 1.9 degrees and increasing the inclination of the inner rail to 4.76 degrees in the curves of the researched radius. We suggest to develop additionally repair profiles of wheel rolling surface for flange height starting from $25 \mathrm{~mm}$ and to optimize wheel tread profile according to the criteria of optimal type and contact place taking into account rail wear at grinding section of track. The repair profiles of the standard documents [10] specify a flange height of $28 \mathrm{~mm}$ within the limits of the flange thickness. In this case, to restore $1 \mathrm{~mm}$ height of the flange, it is 
necessary to remove up to $2 \mathrm{~mm}$ of metal from the rolling damage of the wheel profile. Therefore, the proposed, taking into account the history and operational profiles of the world's railways, can significantly extend the life of wheel pairs and significantly reduce the number of car detachments from trains. In addition, it should be noted that usually repair companies and depots are able to perform turning only one of the repair wheel profiles, removing a significant part of metal from the surface of the wheel rolling profile.

It is recommended to collect statistical data on the wear and shape of wheel sets profiles for the implementation of the proposed methodology for the development of rail repair grinding profiles.

Due to the fact that it is impossible to avoid contact with the flange, we additionally suggest using flange lubricants or grease on locomotives by mobile or stationary machines. According to [18] lubrication will reduce the mutual wear of the wheel flange in 2 times, because the coefficient of friction for a smooth, shiny, un-lubricated side surface of the rail head will be $0.35-0.45$, but at 60 $90 \%$ of the lubricant friction coefficient will be $0.20-0.25$. For passenger trains it is recommended to lubricate the wheel flanges by means of a Locomotive and a standard (Headquarters) railcar in the middle of the train, as lubrication of the rails loses efficiency at a distance of more than $100 \mathrm{~m}$ from the rail lubricator [18]. If the outer rail is subject to heavy lateral wear, mobile or stationary comb lubricators should be used.

\section{Conclusions}

The repair profiles for rail head grinding were modeled for Latvian Railway gauge and their influence on the lateral wear of interacting surfaces of rails and wheels has been estimated. The outcome of this article worn wheel profiles was included in the method of creation of a new repair profile for rail head grinding as a main factor.

Accordindg to the result of study, it can be summarized that:

1. A method for creating repair profiles for rail head grinding has been developed, which is based on the use of real worn profiles of wheel. It allowed: to increase the accuracy of repair profiles for rail grinding, to simulate more accurately single-point contact on a straight track or double-point contact in curves, and as a result to reduce the number of defects of wheel flange on different sections of Latvian Railway tracks.

2. Asymmetrical rail profiles with less wheel and rail interaction and less grinding time have been developed as the recommended profiles for rail grinding. The basic grinding angles for grinding asymmetrical rail profiles are between $2.68^{\circ}$ and $2.41^{\circ}$ for the outer rail and between $2.36^{\circ}$ and $4.61^{\circ}$ for the inner rail. Alternatively, we suggest reducing the tilting of the outer rail to $1.9^{\circ}$ and increasing the tilting angle of the inner rail to $4.76^{\circ}$ on the curves of the investigated radius.

3. Three-dimensional modeling of wheel/rail interaction using the developed rail profile was performed, which allowed to increase the contact areas and as a result to reduce the stress on the outer rail of the curve up to $18 \%$.

4. Changing the grinding angles of the rail, allowed to shift part of the load from the zone of wheel flange wear to the wheel flange root. The displacement reached from 5 to $30 \mathrm{~mm}$, the difference in wheel radii reached $5.6 \mathrm{~mm}$ in one-wheel pair, which improved the fit of wheel pairs by 4 times.

5. The stability coefficient of wheel worn profiles with a flange angle of 66.8 degrees has been calculated in accordance with the condition of rolling on developed asymmetrical profiles of rail. The calculated coefficient was 2.95 , which exceeds the minimum permissible value of 1.5 for freight cars and confirms the stability reserve and operational safety.

The results of the study confirmed the effectiveness of the developed method of creating repair profiles for rail head grinding and developed asymmetric rail profiles. Their use will reduce the side wear of rails, as well as the number of wheel truing on the Latvian Railways.

An interesting area of development of this topic will be the development of an analytical solution for the selection of the optimal rail profile based on wheel wear data on the road section using the existing computer equipment on rail grinding trains. 


\section{References}

[1] Lu Y., Gao Z., Wang J. Study on Influence of Diversified Parameters of Vehicle and Track on Wheel Hollow Wear. Journal Shock and Vibration, Vol. 2018, Article ID 8972615, https://doi.org/10.1155/2018/8972615, 9 July 2018. 11 p.

[2] Pradhan S., Samantaray A.K. A Recursive Wheel Wear and Vehicle Dynamic Performance Evolution Computational Model for Rail Vehicles with Tread Brakes. Journal Vehicles, doi:10.3390/vehicles1010006, vol.1, 17 April 2019, pp. 88-115.

[3] Zeng W., Yang Y., Qiu W.S., Xie H., Xie S.C. Optimization of the target profile for asymmetrical rail grinding in sharp-radius curves for high-speed railways. Advances in Mechanical Engineering. DOI: 10.1177/1687814016687196. journals.sagepub.com/home/adeVol. 9(2), 2017, pp. 1-12.

[4] Способ и устройство определения параметров ремонтного профиля головки рельса (Method and device for determining the parameters of the repair profile of the rail head). Описание изобретения к патенту. RU 2708520 C1., РЖД, 09.12.2019. (In Russian).

[5] Hesam Soleimani, Majid Moavenian Tribological Aspects of Wheel-Rail Contact: A Review of Wear Mechanisms and Effective Factors on Rolling Contact Fatigue. Urban Rail Transit (2017) 3(4): pp. 227-237. DOI: 10.1007/s40864-017-0072-2.

[6] Olofsson U., Telliskivi T. Contact mechanics analysis of measured wheel-rail profiles using finite element method. Proceedings Inst Mech Eng Part F, Journal of Rail and Rapid transit, Vol. 215(2), 03.2001, pp. 65-72.

[7] Бондаренко О. Анализ контактного взаимодействия рельса с вагонным колесом. (Analysis of the contact interaction of the rail with the wheel of car). 2012, НТУ ХПИ. (In Russian).

[8] Иванов И.А., Кушнер В.С., Воробьев А.А., Шадрина Н.Ю., Сорокин П.Г. К вопросу о переспективах использования бандажных колесных пар повышенной твердости. (On the issue of the prospects of using high-hardness bandage wheel sets). ПГУПС, Санкт - Петербург, РФ; ОмГТУ, г. Омск, РФ. 2000. (In Russian).

[9] Сладковский А. К вопросу механики контактного взаимодействия колеса и рельса. (On the mechanics of contact interaction of a wheel and a rail). Сборник Национального горного университета, Vol. 19(4), Днепропетровск, 2004. (In Russian).

[10]Руководящий документ по ремонту и техническому обслуживанию колесных пар. (Guidance document on repair and maintenance of wheelsets with axle boxes of freight cars of the main railways of 1520 (1524) mm gauge. RD VNIIZHT 05.27.01-2017.). Approved 19-20.10. 2017, 67 Protocol. (In Russian).

[11]European Standard. Railway applications. Track. Rail. 10 December 2010. EN 13674$1: 2003+\mathrm{A} 1: 2007$.

[12]Каталог дефектов и повреждений рельсов. (Rail defects and damage catalogue). (Приложение P 736 «Перечень дефектов рельсов и их кодирование». ОСЖД, 27-30 октября 2015. (In Russian).

[13]Инструкция по шлифовке и фрезерованию рельсов в пути и стационарных условиях. (Instructions for grinding and milling rails on the road and stationary conditions). ОАО "РЖД" 29.12.2014 № 3185p. (In Russian).

[14]Классификация рельсов, подлежащих шлифовке, для путей различной ширины колеи. (Classification of rails to be polished for tracks of different gauge.) ОСЖД, 23-25 октября 2018. (In Russian).

[15] Arsenyev I.D., Shevchenko D.V., Borovkov A.I. Finite element modeling and research of contact stresses evolution in process of starting of railway wheel. Вестник пермского государственного технического университета. Механика, Vol.2, УДК: 539.3, ISSN: 2078-6603, 2017, pp. 5-13.

[16] Vorobjev А.A. Contact interaction of a wheel and a rail. УДК 629.4.027, ВЕСТНИК ИрГТУ Vol. 3 (39), 2009, pp. 72-76.

[17] Antipin D.Ya., Kosmodamiansky A.S., Korchagin V.O. Contact spot at conformal interaction of rolling-stock wheel with rail. Proceedings of Bryansk State Technical University. DOI: 10.12737/article_59353e2a4df3e3.59657732. Vol. 2 (55), 2017, pp. 140-145.

[18] Voronin S.V., Korostelyov J.M. The analysis of existing methods of horizontal wear reduction in "wheel-rail" friction pair on curved tracks. IKC3T, Vol.3, 2014. 